Acta vet. scand. $1978,19,441-457$.

From the Department of Surgery, College of Veterinary Medicine, Swedish University of Agricultural Sciences, Uppsala, and the Animal Hospital in Helsingborg, Sweden.

\title{
INVESTIGATIONS OF THE THERAPEUTIC AND PROPHYLACTIC EFFECTS OF DISC EVACUATION IN CASES OF THORACO-LUMBAR HERNIATED DISCS IN DOGS
}

\author{
By \\ Berit Funkquist
}

\begin{abstract}
FUNKQUIST, BERIT: Investigations of the therapeutic and prophylactic effects of disc evacuation in cases of thoraco-lumbar herniated discs in dogs. Acta vet. scand. 1978, 19, 441-457. - The author describes a method for the fenestration and evacuation of degenerated discs in the thoraco-lumbar region of the dog using a lateral approach. This lateral approach makes it possible to reach the entire area of the nucleus pulposus. With the method described, all of the discs in the region of $\mathrm{T}_{9} / \mathrm{T}_{10}-\mathrm{L}_{5} / \mathrm{L}_{6}$ can be evacuated at the same time. The author presents 88 operated cases which showed light or moderate signs of thoraco-lumbar disc herniation, i.e. dogs which displayed pain and/or varying grades of paresis, but retained the ability to walk on their hind legs. The author compares the results of this surgical treatment with the results of the conservative treatment of 128 cases. No significant difference in respect to the mean recovery time was seen between the 2 groups, but the progression of the attack into paraplegia did not occur in the surgically treated material, while such a progression was seen in 4 cases in the conservative material. The greatest value of the disc evacuation, according to the author's investigations, seems to be its prophylactic effect against recurrence. If all of the radiologically degenerated discs in the affected area are evacuated, it appears that one achieves almost complete prophylaxis for some years.
\end{abstract}

spine; spinaldiseases; disc; prolapsus disci; evacuation of the disc.

In 1951 ( $a$ and b), Olsson described a new surgical method for treating herniated discs in dogs. In this method, the disc suspected of causing the acute signs is punctured (fenestrated) either dorsolaterally (herniated disc in the lumbar region or in the lower portion of the thoracic region), ventrolaterally 
(= transthoracically, herniations of dises $\mathrm{T}_{9-10}$ and $\mathrm{T}_{10-11}$ ) or ventrally (herniated discs in the cervical region). The possibilities to effectively evacuate the contralateral and dorsal parts of the thoracic and lumbar discs are - for anatomical reasons - rather restricted by using the Olsson technique (Fig. 1). However, when the therapeutic and prophylactic effect of thoracolumbar disc evacuation is considered, it seems important to use a technique that makes all parts of the disc accessible. A case of recurring disc herniation attributed by myelography to a disc where calcified mass was left at an earlier fenestration, supports the importance of accessibility. The following publications are of special interest when they are looked upon with the foregoing discussion in mind.

In 1960 Leonard described a modification of Olsson's technique. Leonard performs the fenestration with a ventrolateral approach for the thoracic as well as the lumbar region. By this method the disc can be effectively evacuated without damage to the spinal cord. Discs are reached through intercostal and paracostal incisions, respectively. In this method the number of dises able to be reached through the same incision is greatly limited. Therefore an exact localization of the actual herniated disc is necessary, and prophylactic fenestration of a greater number of discs cannot be carried out at the same time.

Northway (1965) describes another variation of fenestration of the lumbar dises by a ventrolateral approach. He makes a longitudinal incision ventral to the transverse processes of the lumbar vertebrae and exposes the lumbar discs by blunt retroperitoneal dissection after dividing the abdominal muscles. With this technique the discs from $T_{13} / L_{1}$ to $L_{6-7}$ inclusive are accessible for fenestration. The drawback of this approach is that discs cranial to $T_{13}$ cannot be reached.

In 1968 Seeman described a technique for thoraco-lumbar disc fenestration with a lateral approach. The discs are reached under the longissimus dorsi after mobilization and elevation of that muscle. A similar technique has been used by Flo \& Brinker (1975). The authors state that the discs from $T_{11-12}$ to $L_{3-4}$ inclusive can be reached in all cases. In certain cases the discs $T_{10-11}$ and $L_{4-5}$ are also accessible by their method. The authors combine the fenestration with simultaneous "chiropractical" manipulation of the vertebral column to promote the extrusion of degenerated disc material. 
In our clinic, fenestration and evacuation of thoraco-lumbar discs have been performed since 1960 according to a special modification of the Olsson technique. A preliminary report of this technique has been given in an earlier paper (Funkquist 1971). The discs are exposed by a dorso-lateral approach. However, the instruments for fenestration and evacuation reach the discs horizontally by blunt penetration of the longissimus dorsi after retraction of the skin (Fig. 2). All the dises from $T_{9-10}$ to $\mathbf{L}_{5-6}$ inclusive can be reached via 1 incision. A similar approach has been proposed by Yturraspe \& Lumb (1973). The latter proposal seems to be based on anatomical studies, and only a few clinical cases are reported.

Only a small number of reports deal with the therapeutic and prophylactic effects of the thoraco-lumbar disc fenestration. In Hoerlein's $(1952,1965,1971)$ works, the effect of disc evacuation alone cannot be evaluated because of the addition of decompression accomplished by hemi-laminectomy. Although Flo \& Brinkman describe the effects of disc fenestration and evacuation in $67 \mathrm{dogs}$ with disc herniation, there is no reference to control material, and the prophylactic effect is not accounted for.

The purpose of this paper is to describe the technique for disc fenestration and evacuation that has been used since 1960

Fig. 1

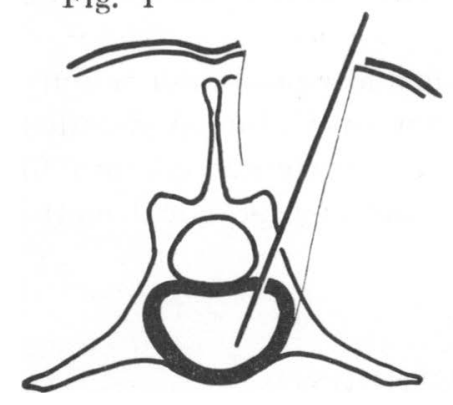

Fig. 2

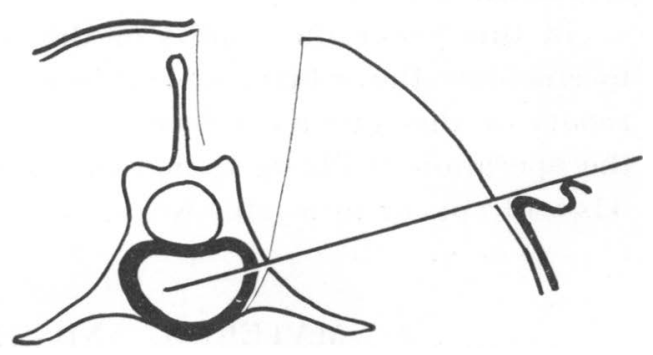

Figure 1. A schematic presentation of the technique of disc fenestration using a dorsolateral approach. The instrument is inserted in a ventromedial direction through the incision between the vertebral prominences and the back muscles.

Figu $r$ e 2. A schematic presentation of the modified disc fenestration and evacuation technique described in the text using a lateral approach. The instrument is inserted through the back muscles (which are bluntly perforated) in a horizontal direction, while the skin is displaced in a lateral and ventral direction. 
in the Department of Surgery, Royal Veterinary College, Stockholm, Sweden, and to account for the therapeutic and prophylactic effects of this treatment in disc herniation. The cases of disc herniation treated conservatively during the same period in the Animal Hospital in Helsingborg, Sweden, are used as control material. Only dogs of chondrodystrophic breeds were used for the study. The reason for this is partly that the actual type of herniated discs (type 1 according to Hansen's nomenclature 1952) occurs only rarely in other breeds, and partly that disc degeneration in the non-chondrodystrophic breeds progresses in a different manner (Hansen 1952). This could influence the results of a surgical removal of the nucleus.

The material was collected only on animals with moderate signs of spinal cord compression, i.e. pain and/or paresis. Animals with paraplegia were not included in the material, since theoretically it seems difficult to expect disc evacuation to have an effect on the compressing forces arising from disc material already present within the spinal canal. This assumption finds support in the studies of Flo \& Brinker mentioned above. In the paraplegic group of dogs the post-operative results reported by these authors are no better than the results that might be expected with conservative treatment (Funkquist 1970). Additional earlier investigations (Funkquist 1962 a and 1970) have shown that decompression by radical laminectomy is an adequate treatment in these cases.

In this paper the results of the study are presented mainly to elucidate the clinical effect of the operation. A detailed report of the local reaction of the vertebral column to the operation, utilizing radiological and patho-anatomical methods will appear in a later work.

\section{MATERIAL AND METHODS}

As mentioned earlier, only chondrodystrophic dogs showing moderate signs of thoraco-lumbar disc herniation, i.e. pain and/or moderate paresis of the hind legs, were included in this material. The degree of paresis was designated to be moderate when the dogs were able to take at least a few steps on their hind legs at the height of an attack.

The operations have been performed by different surgeons with a varying degree of experience. This fact must be taken into 
consideration when judging the risks of the operation from the results reported below.

\section{Surgically treated material}

The surgically treated material consists of $88 \mathrm{dogs}$ on which fenestration with removal of most of the degenerated contents of the discs in the thoraco-lumbar region was done by techniques described below. This was done in the surgical clinic of the Royal Veterinary College in Stockholm during the period August 1, 1960-July 31, 1964. The material consists of 87 Dachshunds and 1 Pekingese; 49 were female and 39 male. The age distribution is presented in Fig. 3. In 38 cases, the signs at the time of operation consisted only of pain limited to the thoraco-lumbar region. In 50 of the cases there was paresis of varying degrees with or without pain. In 8 of the latter cases, the signs worsened during the days preceding the operation, while in 7 cases improvement was noticed. In the remainder of the animals the signs remained stationary during the last part of the pre-operative period. The dogs chosen for the operation have - in addition to the occurrence of the signs described above - fulfilled one or more of the following requirements:

1) More than 10 days' duration of signs.

2) Repeated earlier attacks.

3) Acute onset of the paretic signs with successive aggravation within a few days.

Pre-operative duration of signs for cases with pain alone was $<2$ weeks in $33 \%, 2-4$ weeks in $41 \%$ and $1-3$ months in $26 \%$. The corresponding figures for cases with paresis were $50 \%, 31 \%$ and $19 \%$.

Between August 1, 1964 and February 28, 1967, operations were performed on 52 additional dogs. These have not been subjected to follow-up examination but they are used below to elucidate the risk of operational complications.

Radiological examination

A routine pre-operative radiological examination was carried out on all dogs. In choosing the discs for surgery the author primarily attempted to find the disc thought to be the cause of the clinical signs. The following radiological changes - alone or in various combinations - have been considered indications 
for a particular disc being responsible for the signs in question, irrespectively of whether the disc showed remaining calcified masses or not:

a) Narrowing of the disc (particularly if assymetrical).

b) Sclerosis of adjacent portions of the vertebrae.

c) Increased density in the spinal column dorsal to the disc.

d) Radio-opaque streak (rupture) dorsally in the disc.

For prophylactic reasons, it was regarded as desirable to evacuate other degenerated, but not prolapsed discs in the thoracolumbar region. An increased density in the disc (degenerative calcification) has been used as the criterion of degeneration.

In 8 cases, subarachnoid myelography (Funkquist $1962 \mathrm{~b}$ ) has been done 3-8 days prior to fenestration in order to localize the site of spinal cord compression with certainty. In all cases where myelography was done, a filling defect of the subarachnoid space was localized over a certain disc indicating the presence of limited spinal cord compression.

Surgical procedure

Anesthesia was induced with i.v. pentothal and maintained with halothane and nitrous oxide. The dog breathed spontaneously; however, in those cases where the pleura was injured (not uncommon in fenestrations of discs $\mathbf{T}_{9-10}, \mathbf{T}_{10-11}$ and $\mathbf{T}_{11-12}$ ), respiration was assisted manually. The operation was performed with the dog in abdominal recumbency. A longitudinal skin and fascial incision was made over the articular processes on the left side of the vertebrae within the affected area. The affected discs, destined for evacuation, were localized using the last set of ribs as a point of orientation (one should observe that the last thoracic vertebra occasionally lacks 1 or both ribs). Using a periosteal elevator, the anterior border of the head of the rib, or in the lumbar region the anterior border of the base of the transverse process, was dissected free (subperiostally) to the vertebral junction. Using this as a point of orientation, the left lateral surface of the disc was exposed. The disc is situated immediately in front of and sometimes a little medially to the rib junction or in front of the base of the transverse process, respectively. By dissecting subperiosteally, one avoids the danger of damaging the intervertebral artery and the intervertebral nerves. One should dissect radically so that a good view of the 
lateral surface of the disc is obtained. The disc's ventral surface was located by means of a probe. A Steinmann pin of $2-3 \mathrm{~mm}$ in diameter was then inserted horizontally into the disc in the middle of its lateral surface. In order to insert the instrument into the disc horizontally, it must first pass through the back muscles. This was easily done through the original skin incision due to the fact that the elastic subcutaneous tissue characteristic in the dog makes it possible to retract the lateral edges of the skin incision far below the level of the disc (Fig. 4). One should observe a certain amount of caution so that the pin is not mistakenly inserted through the foramen intervertebrale (in such an event, the instrument has been inserted too far cranially and dorsally). During fenestration of discs $T_{9-10}, T_{10-11}$ and $T_{11-12}$, the pleura was occasionally perforated; therefore, the instrument should be inserted during expiration so that the lungs are not injured. If great amounts of air are sucked in, artificial respiration should be maintained during the remainder of the operation. The degenerated contents of the disc were removed as completely as possible by curette which inserted through the opening in the disc made by the Steinmann pin. Horizontal direction of the curette into the disc was obtained by blunt perforation of the back muscles as described above for the Steinmann pin. All of the degenerated discs caudal to $\mathbf{T}_{9}$ and cranial to $L_{6}$ could be reached through the same incision with this technique. After completion of the disc removal, the fascia and skin were sutured. Following the operation, the dog was kept resting in a cage for 10-14 days. Thereafter increasing amounts of exercise were allowed.

The scope of the operation

In principle, it has been atempted to evacuate all of the calcified dises from $\mathrm{T}_{9-10}$ to $\mathrm{L}_{5-6}$ inclusive. If the time of the operation was prolonged because of technical difficulties (hemorrhage, obesity) or due to the limited experience of the surgeon, the operation in some cases was stopped before all of the affected discs within the region were evacuated. The number of discs fenestrated in the same operation varied between 1 and 6 . The number of different evacuated discs in the case material is reported in Table 1 . The number of degenerated discs remaining within the affected area $\left(\mathrm{T}_{9}-\mathrm{L}_{7}\right)$ may be seen in Table 6 . In 27 cases, the degree of disc evacuation was checked by a post- 
Table 1. The frequency of surgical evacuations of various discs in the thoraco-lumbar region.

\begin{tabular}{lcccccccccccc}
\hline & $\begin{array}{c}\text { Total } \\
\text { number }\end{array}$ & $\mathrm{T}_{9-10}$ & $\mathrm{~T}_{10-11}$ & $\mathrm{~T}_{11-1}$ & $\mathrm{~T}_{12-13}$ & $\mathrm{~T}_{13-} \mathrm{L}_{1}$ & $\mathrm{~L}_{1-2}$ & $\mathrm{~L}_{2-3}$ & $\mathrm{~L}_{3-1}$ & $\mathrm{~L}_{4-5}$ & $\mathrm{~L}_{5-0}$ \\
\hline $\begin{array}{l}\text { Number of } \\
\text { surgical } \\
\text { evacuations }\end{array}$ & 298 & 1 & 27 & 51 & 59 & 49 & 38 & 31 & 25 & 15 & 2 \\
\hline
\end{tabular}

operative radiological examination within 4 days of the operation. These cases have shown a clear but varying reduction of the radio-opaque material in the disc. In a few cases, where additional post-operative radiography was done within 14 days, a further reduction or complete disappearance of the radioopaque contents was seen (a detailed report of the radiological changes induced by the operation will appear in a later publication).

Follow-up examination

In 81 of the 88 cases, a follow-up concerning the post-operative period was done in the form of a telephone interview. In 37 of these cases, a clinical follow-up including a radiological examination was done. The length of observation time has varied between 3 months and 6 years. The distribution of the material over the observation period is seen in Table 2 .

T a b le 2. The distribution of the surgical and conservative material within the respective observation times. The table comprises only

dogs with a post-operative observation time of 3 months or more.

\begin{tabular}{lccccccc}
\hline & \multicolumn{7}{c}{ The number of animals with observation times of } \\
\cline { 2 - 8 } & $<1 / 2$ & $1 / 2-<1$ & $1-<2$ & $2-<3$ & $3-<4$ & $4-<5$ & $5-<6$ years \\
\hline $\begin{array}{l}\text { Surgical } \\
\text { treatment } \\
(\mathrm{n}=81)\end{array}$ & 81 & 80 & 80 & 65 & 47 & 21 & 10 \\
$\begin{array}{l}\text { Conservative } \\
\text { treatment } \\
(\mathrm{n}=106)\end{array}$ & 106 & $\mathbf{1 0 4}$ & 100 & 81 & 56 & 43 & 18 \\
\hline
\end{tabular}

\section{Conservatively treated material}

The conservatively treated material consists of 128 dogs which were treated for the above described signs of thoracolumbar herniated disc in the Animal Hospital in Helsingborg 
from August 1, 1960 to July 31, 1964. The breed distribution was the following: 108 Dachshunds, 13 Pekingese, 6 Cocker Spaniels and 1 French Bulldog. The material consists of 78 females, 49 males and 1 animal without mention of sex. The age distribution is given in Fig. 4. In 54 of these cases, the signs observed at the first examination at the animal hospital consisted of pain only, while in 74 cases, paresis either with or without pain was seen. The duration of the signs before the consultation was $<2$ weeks in about $95 \%$ and $2-4$ weeks in about $5 \%$. Because of the organization of the veterinary service in the region supplying the Animal Hospital in Helsingborg there has been, unforlunately, some selection, in that animals with rapidly (during $1-2$ days) progressing paralysis usually did not arrive at the hospital until paraplegia had developed and therefore were excluded from the material. The diagnosis was made on the grounds of a clinical examination which, in some of the cases, was supplemented by a routine radiological examination. The treatment consisted of rest, without special fixation of the animal, combined with prophylactic or therapeutic treatment for urinary tract infection
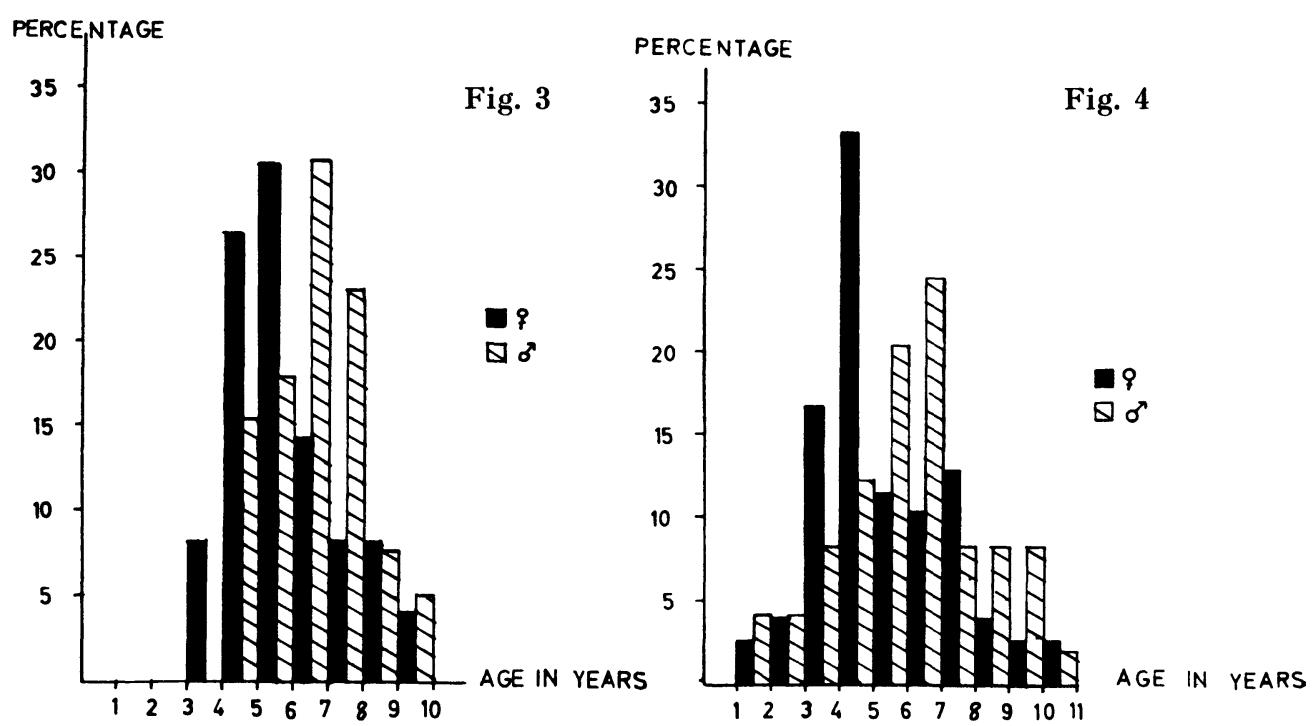

Figure 3. The percentage distribution of the surgically treated material.

F ig u r e 4. The percentage distribution of the conservatively treated material. 
due to urine retention. Anti-inflammatory drugs (e.g. Phenylbutazone, cortico-steroids) and/or analgesics and sedatives were given in most cases. In many cases, Vitamin B was administered. Some of the animals obtained subcutaneous injection of iodinated casein (Yatrén).

In 106 of the cases, a follow-up investigation in the form of a telephone interview was carried out regarding the duration of the signs as well as the occurrence of prior and later altacks. The observation periods have varied from 3 months to 6 years. The distribution of the material over the observation period is seen in Table 2.

\section{RESULTS}

\section{Therapeutic effect}

The total outcome of the surgical and conservative treatment, respectively, is shown in Table 3 . The effect on the recovery time is shown in Table 4. Eight of the surgical cases showed paresis in progress when operated upon. In spite of that they recovered completely (after a temporary impairment).

T a b le 3. A survey of the treatment results (final outcome) with surgical $^{\star}$ or conservative ${ }^{\star \star}$ treatment.

\begin{tabular}{|c|c|c|c|c|c|c|c|}
\hline \multirow{2}{*}{$\begin{array}{c}\text { Comple- } \\
\text { tely } \\
\text { reco- } \\
\text { vered }\end{array}$} & \multirow{2}{*}{$\begin{array}{c}\text { Remaining } \\
\text { mild pare- } \\
\text { sis in } 1 \\
\text { hind leg. } \\
\text { Otherwise } \\
\text { satisfactory } \\
\text { results }\end{array}$} & \multicolumn{2}{|c|}{$\begin{array}{l}\text { Progression } \\
\text { to paralysis }\end{array}$} & \multirow{2}{*}{$\begin{array}{l}\text { Died } \\
\text { during } \\
\text { the } \\
\text { opera- } \\
\text { tion }\end{array}$} & \multicolumn{2}{|c|}{ Unimproved } & \multirow{2}{*}{$\begin{array}{c}\text { Died } \\
\text { with an } \\
\text { inter- } \\
\text { current } \\
\text { disease } \\
\text { (Im- } \\
\text { proved) }\end{array}$} \\
\hline & & $\begin{array}{c}\text { eutha- } \\
\text { nized }\end{array}$ & $\begin{array}{c}\text { died } \\
\text { with } \\
\text { myelo- } \\
\text { malacia }\end{array}$ & & $\begin{array}{l}\text { eutha- } \\
\text { nized }\end{array}$ & $\begin{array}{c}\text { selec- } \\
\text { ted for } \\
\text { opera- } \\
\text { tion }\end{array}$ & \\
\hline
\end{tabular}

Surgically

treated

animals

$(\mathrm{n}=80)$

(nonserva-

tively trea-

ted animals

$(\mathrm{n}=117)$

$76^{\star \star \star} \quad 3$

1

* The 3 dogs subjected to technical accidents (instrumental cord damage) and 5 dogs with unknown post-operative courses are excluded from the table.

* * Eleven dogs with unknown outcome are excluded from the table.

*** Six of the dogs treated surgically and 13 of the dogs treated conservatively showed temporary mild stiffness or difficulty in movement in the cold or after exertion. 
T a b l e 4. The recovery time for 69 dogs following surgical treatment (disc evacuation) and for 59 conservatively treated cases. Only dogs with stationary signs at the time of hospitalization and with known recovery interval have been included.

\begin{tabular}{|c|c|c|c|c|c|c|c|c|c|c|}
\hline & \multirow{3}{*}{$\begin{array}{c}\text { Total } \\
\text { number }\end{array}$} & \multicolumn{9}{|c|}{ The number of animals with a recovery time of } \\
\hline & & \multicolumn{4}{|c|}{ weeks } & \multicolumn{4}{|c|}{ months } & \multirow{2}{*}{$\frac{\text { years }}{1-2}$} \\
\hline & & $<1$ & $1-<2$ & $2 \cdot<3$ & $3-<4$ & $1-<2$ & $2 \cdot<3$ & $3-<6$ & 6 & \\
\hline $\begin{array}{l}\text { C a ses w it } \\
\text { p a in a l o n } \\
\text { Surgically } \\
\text { treated } \\
\text { animals }\end{array}$ & 27 & 1 & 14 & 6 & $\mathbf{3}$ & 2 & & 1 & & \\
\hline $\begin{array}{l}\text { Conserva- } \\
\text { tively trea- } \\
\text { ted animals }\end{array}$ & 19 & 8 & 7 & 2 & & & 2 & & & \\
\hline $\begin{array}{l}\text { Cases of } \\
\text { p a r e s i s* } \\
\text { w ith or } \\
\text { w ith o u t } \\
\text { p a i n } \\
\text { Surgically } \\
\text { treated } \\
\text { animals }\end{array}$ & 42 & & 17 & 5 & 12 & 4 & 1 & 1 & 2 & \\
\hline $\begin{array}{l}\text { Conserva- } \\
\text { tively trea- } \\
\text { ted animals }\end{array}$ & 40 & 1 & 6 & 12 & 5 & 9 & & 3 & 2 & 2 \\
\hline
\end{tabular}

* Note. The material of this paper comprises only dogs with remaining ability to walk.

2. Prophylactic effect against recurrence

In the operative material, recurrences were observed in $\mathbf{1 4}$ of the 81 cases, that is $\mathbf{1 7} \%$, while the corresponding figures for the 104 conservatively treated cases are 50 and $48 \%$, respectively (Table 5). This difference is highly significant ( $\chi^{2}$-test).

The observed recurrences were also studied in respect to the manner in which their frequency was influenced by the number of unevacuated, calcified discs which remained after the operation. This investigation was done on 79 cases where the radiographs were suitable. The results are presented in Table 6.

An attempt was made to radiologically localize the disc herniation causing recurrence in 7 of the cases within the operative material using the criteria described in Materials And Methods. All the dises suspected (with 1 exception) showed a radiologically demonstrable calcification at the time of operation. None of them had been subjected to evacuation. 
Table 5. A comparison between the surgically and conservatively treated material in respect to the risk of recurrence. Concerning observation time for the material see Table 2 . The table comprises animals with a known observation time longer than 3 months.

\begin{tabular}{lccc}
\hline & $\begin{array}{c}\text { Number of ani- } \\
\text { mals observed } \\
\text { following the } \\
\text { treated attack }\end{array}$ & $\begin{array}{c}\text { Observed first recurrences } \\
\text { (irrespective of observa- } \\
\text { tion time) }\end{array}$ \\
\cline { 3 - 4 } & & number & per cent \\
\hline $\begin{array}{l}\text { S u r g i c a l l y } \\
\text { t r e a t e d a n i m a l s }\end{array}$ & 34 & 5 & 15 \\
$\begin{array}{l}\text { Cases with pain alone } \\
\text { Cases of paresis with } \\
\text { or without pain }\end{array}$ & 47 & 9 & 19 \\
$\begin{array}{l}\text { Total } \\
\text { C o n s e r v a t i v e l y } \\
\text { t r e a t e d m a t e r i a } 1\end{array}$ & 81 & 14 & 17 \\
Cases with pain alone & & & \\
Cases of paresis with & 43 & 24 & 56 \\
or without pain & 61 & 56 & 43 \\
Total & 104 & & 48 \\
\hline
\end{tabular}

$\chi^{2}=24.5^{\star \star \star}($ d.f. $=1)$

\section{Operational risks}

Of the 88 dogs operated upon, 1 died in connection with the operation (Cardiac arrest). In 3 cases, there was spinal cord damage during the operation. This was caused by the fenestration instrument mistakenly entering the vertebral canal through foramen intervertebrale ${ }^{\star}$. One of these 3 dogs was euthanized 15 days after the operation because of paralysis which did not appear to be regressing. Both of the remaining animals showed a mild paresis in 1 hind leg. One of those recovered after 6 months, but the other one still showed paresis when examined after $4 \frac{1}{2}$ years.

Another type of complication (which could not be regarded as a technical error) was found in 1 case. This dog developed 12 days after the operation signs of pain at the thoraco-lumbar junction. An osteolytic lesion could be seen on radiography in

* In each of these cases, the surgeon had a limited experience of surgery on the vertebral column. 
Table 6. The frequency and distribution of the first recurrence during the observation time following surgical treatment. The table comprises only dogs with complete X-ray examination and with a known observation time longer than 3 months.

Numerator: The number of first recurrences observed during the stated line.

Denominator: The number of animals reaching the stated time without a previous recurrence.

The recurrence frequency has been arranged relative to the number of calcified discs (at the time of operation) which were not evacuated.

\begin{tabular}{|c|c|c|c|c|c|c|c|c|c|c|}
\hline \multirow[t]{2}{*}{$\begin{array}{l}\text { Number of } \\
\text { unevacuated } \\
\text { radiologically } \\
\text { calcified } \\
\text { discs within } \\
T_{\boldsymbol{\theta}}-L_{\bar{\imath}}\end{array}$} & \multirow[t]{2}{*}{$\begin{array}{c}\text { Total } \\
\text { num- } \\
\text { ber } \\
\text { of } \\
\text { dogs }\end{array}$} & \multirow{2}{*}{$\begin{array}{c}\text { Number of } \\
\text { unevacuated } \\
\text { radiologically } \\
\text { noncalcified } \\
\text { discs within } \\
\mathrm{T}_{9}-\mathrm{L}_{7} \\
\text { (Mean for } \\
\text { the group) }\end{array}$} & \multirow{2}{*}{$\begin{array}{c}\text { Total } \\
\text { number } \\
\text { of } \\
\text { observed } \\
\text { first } \\
\text { recur- } \\
\text { rences }\end{array}$} & \multicolumn{7}{|c|}{$\begin{array}{l}\text { The frequency of first recurrence encountered } \\
\text { after an observation time of }\end{array}$} \\
\hline & & & & $<1$ & $1 \cdot<2$ & $2-<3$ & $3-<4$ & $4-<5$ & $5<6$ & years \\
\hline 6 & 1 & 4 & 1 & $0 / 1$ & $1 / 1$ & & & & & \\
\hline 4 & 4 & 3.2 & 3 & $0 / 4$ & $3 / 4$ & $0 / 1$ & & & & \\
\hline 3 & 10 & 4.1 & 4 & $0 / 10$ & $2 / 10$ & $1 / 7$ & $1 / 5$ & $0 / 2$ & $0 / 1$ & \\
\hline 2 & 18 & 5.7 & 4 & $1 / 18$ & $2 / 17$ & $1 / 17$ & $0 / 10$ & $0 / 2$ & $0 / 1$ & \\
\hline 1 & 20 & 6.4 & 1 & $1 / 20$ & $0 / 19$ & $0 / 14$ & $0 / 10$ & $0 / 5$ & $0 / 1$ & \\
\hline 0 & 26 & 7.4 & 1 & $0 / 26$ & $0 / 25$ & $0 / 22$ & $0 / 18$ & $1 / 9$ & $0 / 5$ & \\
\hline Total & 79 & & 14 & $2 / 79$ & $8 / 76$ & $2 / 61$ & $1 / 43$ & $1 / 18$ & $0 / 8$ & \\
\hline
\end{tabular}

those portions of the vertebrae which bordered on 2 of the 3 discs fenestrated. The pain signs disappeared completely within 10 days while the radiological osteolysis remained during this time.

Of the additional 52 dogs operated upon from August 1, 1964 to February 28, 1967 (not subjected to follow-up examination), 1 died 4 days after the operation with circulatory insufficiency, and 1 died of pleurisy 5 days post-operatively. One of the 52 dogs showed post-operative recurrence of pain and paresis accompanied by a temperature increase. These signs were traced to a radiologically demonstrable discospondylitis in 3 fenestrated discs and in portions of the bordering vertebrae. This complication probably had an infectious etiology since signs of wound infection were seen during the first post-operative weeks. The dog was pain-free and regained normal motility after about 4 months of antibiotic treatment. No other serious complications 
occurred in those cases operated on after August 1, 1964. As many as 8 discs were removed at one time without any negative clinical effect.

\section{DISCUSSION}

1. All animals with progressive signs of disc disease at the time of surgery recovered completely. There is no comparable control material and the case material is too small to draw definitive conclusions. The results, however, do suggest that therapy by early disc evacuation should be considered in future cases, since according to prior studies (Funkquist 1962 a) about $35 \%$ of the cases of disc herniation that develop paraplegia, do so slowly (during 1-7 days), so that a disc evacuation could be performed before paraplegia occurs.

In the animals in which the signs were stationary at the time of hospitalization, there was no significant difference between the surgical and the conservative material in the mean length of recovery time (Table 4 ). It should be noted, however, that 4 of the animals, treated conservatively, developed paraplegia, while this outcome was not observed in the surgical material. The fact that the surgical cases were strongly selected for longlasting or serious signs, while the conservative cases were chosen at random, is an additional factor pointing at the benefits of surgical treatment.

2. Recurrence was observed in a total of $48 \%$ of the conservatively and in $17 \%$ of the surgically treated animals. As the distribution of the material over the observation time is generally the same for both of the groups (Tables 2, 6 and 7), the numbers are directly comparable and show a definite advantage of surgical prophylaxis against recurrence. It may be seen from Table 6

Table 7. The frequency and distribution of the first recurrence during the observation time following conservative treatment. The table comprises only animals with a known observation time longer

than 3 months. See Table 6 for an explanation of the symbols.

\begin{tabular}{|c|c|c|c|c|c|c|c|c|}
\hline \multirow{2}{*}{$\begin{array}{l}\text { Total } \\
\text { number } \\
\text { of dogs }\end{array}$} & \multirow{2}{*}{$\begin{array}{l}\text { Total } \\
\text { number } \\
\text { of first } \\
\text { recur- } \\
\text { rences }\end{array}$} & \multicolumn{7}{|c|}{$\begin{array}{c}\text { The frequency of first recurrence encountered } \\
\text { after an observation time of }\end{array}$} \\
\hline & & $<1$ & $1-<2$ & $2-<3$ & $3 \cdot<4$ & $4-<5$ & $5-<6$ & years \\
\hline 104 & 50 & $18 / 104$ & $21 / 86$ & $8 / 55$ & $2 / 34$ & $1 / 27$ & $0 / 11$ & \\
\hline
\end{tabular}


that the animals in which all of the calcified discs in the area of $T_{9}-L_{7}$ were evacuated had a lower risk of recurrence than those where calcified discs were left unevacuated. Following total ,clearing" of the back, it seems justifiable to count on a nearly $100 \%$ freedom from recurrence, at least for several years. Without surgical prophylaxis, about $50 \%$ of the dogs which had had one or more attacks could expect a recurrence within a 3 year period.

Theoretically a prophylactic disc evacuation should, even in the case of normal discs in an area prone to herniations $\left(T_{11}-L_{2}\right)$, diminish the risk of recurrence. However, it is not known whether a normal disc, which is fenestrated in the breeds under discussion, can still undergo the type of degeneration which is a prerequisite for disc herniation. Disregarding this fact the practical need for such an evacuation of normal discs seems insignificant. The reason for this is partly that as stated above, the frequency of recurrence after evacuation of most of the radiologically degenerated discs is very low and partly that the disc which could be responsible for the ensueing recurrence was degenerated already at the time of the operation in 6 of the 7 cases investigated. It seems that most of those discs, which in a certain individual are predestined to the type of degeneration which involves risk of disc herniation, show radiological calcification already at the time when the disc symptoms bring the animal to the attention of the surgeon.

3. If one includes the material operated upon after August 1, 1964, the mortality rate is $2.1 \%$. This figure is not remarkably high if one considers that the mean age of the material is high and that obesity is common in Dachshunds, the dominating breed. All of the serious complications including 2 of the 3 cases of death, were found in dogs treated by surgeons with limited experience in surgery of the vertebral column. This leads one to believe that operational risks can be greatly reduced if the operation is performed by a specially trained staff.

\section{ACKNOWLEDGEMENTS}

The radiographs taken at the Department of Clinical Radiology at the College of Veterinary Medicine have kindly been placed at my disposal for closer study by Professor S.-E. Olsson. Mrs. Inga Lindgren, from the same department has given generously of her time in the taking of the necessary radiographs. Miss Emy Persson and Miss 
Margit Johansson at the Animal Hospital in Helsingborg, as well as Miss Ann-Marie Hoff and Miss Marianne Sitte at the College of Veterinary Medicine, have given outstanding help in the investigation of the animals.

\section{REFERENCES}

Flo, G. L. \& W. O. Brinker: Lateral fenestration of thoraco-lumbar discs. J. Amer. Anim. Hosp. Ass. 1975, 11, 619-626.

Funkquist, B.: Thoraco-lumbar disk protrusion with severe cord compression in the dog. Acta vet. scand. 1962 a, 3, 256-274, 317343 and $344-368$.

Funkquist, B.: Thoraco-lumbar myelography with water-soluble contrast medium in dogs. J. small Anim. Pract. 1962 b, 3, 53-66 and $67-73$.

Funkquist, B.: Decompressive laminectomy in thoraco-lumbar disc protrusion with paraplegia in the dog. J. small Anim. Pract. 1970, 11, 445-451.

Funkquist, B.: Prolapsus disci intervertebralis in the dog. Medlemsbl. danske Dyrlægeforen. 1971, 54, 889-895.

Hansen, H.-J.: A pathologic-anatomical study on disc degeneration in dog. Acta orthop. scand. 1952, Suppl. 11.

Hoerlein, B. F.: The treatment of intervertebral disc protrusions in the dog. Proc. Amer. vet. med. Ass. 1952, 89, 206-212.

Hoerlein, B. F.: Canine Neurology (Chapter 10), W. B. Saunders Co., Philadelphia and London 1965.

Hoerlein, B. F.: Canine Neurology (Chapter 12). W. B. Saunders Co., Philadelphia and London 1971.

Leonard, E. P.: Orthopedic Surgery of the Dog and Cat. W. B. Saunders Co., Philadelphia and London 1960.

Northway, R. B.: A ventrolateral approach to lumbar intervertebral disc fenestration. Vet. Med. 1965, 60, 884-893.

Olsson, S.-E.: Observations concerning disc fenestration in dogs. Acta orthop. scand. 1951 a, 20, 349-356.

Olsson, S.-E.: On disc protrusion in dog. Acta orthop. scand. $1951 \mathrm{~b}$, Suppl. 8.

Seeman, C. W.: A lateral approach for thoracolumbar disc fenestration. Mod. vet. Pract. 1968, 49, 73-74.

Yturraspe, D. J. \& W. V. Lumb: A dorso-lateral muscle-separating approach for thoraco-lumbar intervertebral disk fenestration in the dog. J. Amer. vet. med. Ass. 1973, 162, 1037-1040.

\section{SAMMANFATTNING}

Undersökningar över terapeutisk och profylaktisk effekt av diskutrymning vid thorako-lumbalt diskbråck hos hund.

Författaren beskriver en metod för att lateralt ifrån utrymma degenererade disker i thorako-lumbalregionen hos hund. Den laterala approachen gör det möjligt att nå nucleus pulposus i hela dess utsträckning. Med den beskrivna metoden kan samtliga disker i om- 
rådet $T_{9} / T_{10}-L_{5} / L_{6}$ utrymmas $i$ en seans. Författaren redogör för 88 opererade fall, vilka visat lätta eller medelsvåra symptom på thorako-lumbalt diskbråck, dvs hundar som företett smärta och/eller varierande grad av pares, men dock kunnat gå åtminstone något steg på bakbenen. Författaren jämför resultaten vid denna kirurgiska behandling med resultaten av konservativ behandling av 128 fall. Någon påtaglig skillnad med avseende på tillfriskningstiden föreligger ej mellan de båda materialen. Utveckling av anfallet till paraplegi har ej förekommit $i$ det kirurgiskt behandlade materialet, medan sådan försämring förekommit i 4 fall i det konservativa materialet. Diskutrymningens största värde tycks enligt författarens undersökningar ligga i dess recidivprofylaktiska effekt. Om samtliga röntgenologiskt degenererade disker $\mathrm{i}$ det aktuella området utrymmes, förefaller det, som om man skulle uppnå en nästan $100 \%$-ig recidivprofylax för de närmaste åren.

\section{(Received April 10, 1978).}

Reprints may be requested from: Berit Funkquist, the Department of Surgery, College of Veterinary Medicine, Swedish University of Agricultural Sciences, S-750 07 Uppsala, Sweden. 